\title{
Inkesten emaitzetan oinarrituriko balorazio-adierazle orokorra sortzeko proposamena
}

\author{
Ane Zarragoitia, Arantza Urkaregi ${ }^{1}$ \\ ${ }^{1}$ Matematika Aplikatua, Estatistika eta Ikerkuntza Operatiboa Saila. \\ Euskal Herriko Unibertsitatea (UPV/EHU) \\ anezarra@hotmail.com; arantza.urkaregi@ehu.es
}

Laburpena: Ebaluazio-tresna moduan erabiltzen direnean, inkestek eragozpenak sortzen dituzte beren informazio guztiaren ustiapenean. Askotan aldagai anitzeko analisiko tekniken berri ez izateak edota inkestek jasotako informazio guztia adierazle orokor batean bildu behar izateak daraman zailtasuna dela eta, inkesten datuen analisi estatistikoak bi aldagai uztartzen dituzten kontingentzi tauletara edo analisi deskribatzaileetara mugatzen da. Aldiz, azterketa honetan Korrespondentzia Anizkoitzen Analisia erabili da galdetegi bateko galderen modalitateak ordenatu eta beraien koordenatu faktorialeetatik abiatuz, datuetan jasotako informazio guztia biltzen duen tresna bat sortzeko, hau da, balorazio-adierazle orokor bat eraikitzeko. Adierazle hau automatikoki lortu ahal izateko, R-n programa bat garatu da. Eskuratutako adierazlean eragina duten faktoreak aztertu dira, hau hobekuntzarako erabilgarria eta fidagarria den tresna bilakatzeko. Aplikazio guztia, aurrera eraman da barruko mediku egoiliarren (BAME) programaren prestakuntza ebaluatzeko balioztatua zegoen inkesta baten datuekin.

\begin{abstract}
When the surveys are used as an assessment tool, the problem lies in the analysis of all the information gathered. Often, as we don't know multivariate techniques or as it is difficult to summarize all the information collected in surveys into an index, the statistical analysis of them is limited to a descriptive analysis. In this assignment, with a view to building an overall index that summarizes the assessment of a survey, we have performed a Multiple Correspondence Analysis (MCA) to arrange the options of the questions and from their coordinates develop a tool that garners all the information. To obtain this indicator automatically, a program in $\mathrm{R}$ has been developed. The factors that have had an influence on the obtained indicator have been analysed, so that this index will become a useful and reliable tool. The whole application has been undertaken with validated data from a survey to evaluate the MIR training programme.
\end{abstract}




\section{SARRERA}

Estatu espainiarrean, graduondoko medikuntza-prestakuntza sistemak, BAME barruko mediku egoiliarraren irudian oinarrituta, balio handiko ekarpena egin du osasun-sistema nazionalaren hobekuntza eta garapenean. Hori dela eta, onetsi da BAMEren prestakuntzan arazoak antzeman eta konponbideak aurkitzea ahalbidetuko duen ebaluazio-inkesta aldiro egitea.

Inkestek, abantaila handiagoak aurkezten dituzte informazioa lortzeko beste bide batzuek baino. Hala ere, askotan aldagai anitzeko analisiko tekniken berri ez izateak edota inkestek jasotzen duten informazio guztia adierazle orokor batean biltzeak dakarren zailtasuna dela medio, ez da behar adina etekinik ateratzen. Horregatik, lan honek helburu modura hartu du adierazle berri bat garatu eta batez ere balioestea. Horretarako, 2004-2010 tartean BAMEek Gurutzetako Unibertsitate Ospitalean egindako inkesten emaitzetatik abiatu gara; adierazleak BAME programaren balorazioa automatikoki jasoko du eta etorkizunean programaren hobekuntzarako baliozko tresna bihurtu daitekeelakoan gaude.

\section{METODOLOGIA}

Egindako ikerlan honek aztergai hartu dituen inkestek, barne mediku egoiliarrek zerbitzuan jasotako prestakuntzaren balorazio bat jasotzen dute. Prestakuntza hori, 2004 eta 2010 tartean bi urtean behin jaso zuten Gurutzetako Unibertsitate Ospitalean.

2004. urtean 136 barruko mediku egoiliarrek bete zuten inkesta, 2006an 251 medikuk, 2008an 229 medikuk eta 2010an 233 medikuk; guztira 849 inkesta izan ziren. Inkesta bakoitza, arlo ezberdinetako 26 galderak osatzen dute, ebaluatzeko 20k eta informazioko beste 6k. (1 Eranskina).

Ebaluazio-galderen erantzun aukerak honako hauek izan ziren: Bikaina Egokia - Eskasa - Oso eskasa. Erantzunik eza ere, galdera bakoitzaren aukera modura bildu da.

\section{Aldagai anitzeko azterketa deskribatzailea}

Korrespondentzia Anizkoitzen Analisian dimentsio txikiagoko espazio batean laburtu nahi dira aztertzen ditugun datuak. Datuek, $n$ alek $p$ galderei emandako erantzunak direlarik, $(n \times p)$ datu matrizea osatzen dute.

Matrize honen lerroek, $\mathrm{R}^{p}$ espazioko $n$ ale-puntuen hodeia definitzen dute, eta aldi berean, zutabeek, $\mathrm{R}^{n}$ espazioko $p$ aldagai-puntuen hodeia. Aldagaipuntuen (ale-puntuen) hodeiari hobekien egokitzen zaion azpiespazioa doitzeko irizpidea, proiekzioen karratuen batura haztatua maximizatzean datza. 
Korrespondentzia Anizkoitzen Analisiak, posible egiten du «aldagai aktiboak» eta «aldagai argigarriak» bereiztea. Aldagai aktiboek ardatz faktorialen kalkuluan hartzen dute parte; aldagai argigarriek aldiz, interpretaziorako lagungarriak gertatzen dira, aldagai aktiboen bidez kalkulaturiko ardatz faktorialen gainean proiektatzen baditugu.

Aldagai aktiboak aukeratu ondoren, $\mathbf{B}=\mathbf{Z}^{\mathbf{t}} \cdot \mathbf{Z}$ Burten matrizearen balio eta bektore propioak kalkulatu behar ditugu. Bertan, $\mathbf{Z}$ kodetze disjuntibo osoz eraturiko matrizea da, hots, Q aldagai kualitatibo baditugu, horrela osatuko dugu $\mathbf{Z}$ :

$$
\mathbf{Z}=\left(\mathbf{Z}_{1}, \mathbf{Z}_{2}, \ldots, \mathbf{Z}_{\mathrm{Q}}\right) \text {, non } \mathbf{Z}_{q}=\left(z_{i j}^{q}\right)
$$

$z_{i j}^{q}=1$ baldin eta $i$ indibiduoak $q$ kuestioaren $j$ modalitatea aukeratzen badu, eta $z_{i j}^{q}=0$ beste kasuetan. Beraz, $\mathbf{Z}_{q}$ azpitaularen lerro bakoitzean, 1 bakarra dago eta beste elementu guztiak 0 dira.

Bektore propio horiek izango dira, hain zuzen, puntu hodeiari hobekien egokitzen zaion azpiespazioa sortzen duten ardatz faktorialak.

Korrespondentzia Bakunen Analisian, faktoreei dagozkien inertziek interpretazio estatistikoa dute, baina Korrespondentzia Anizkoitzen Analisian kontuan hartu behar dugu balio propio guztiek ez dutela eragin berbera; faktore askoren interpretazioa berriro errepikatzen da maila altuagoa duen faktore batean, eta gainera, lorturiko balio propioei inertzi tasa txikiak egokitzen zaizkie $\mathrm{Z}$ matrizearen egituraren ondorioz. Hori dela eta, ematen duten informazioaren kalitatearekin parekatuz ikuspegi ezkorra ematen digute.

Arazo hori konpontzeko Benzécrik kontuan hartu zuen Korrespondentzia Bakunen Analisian eta Korrespondentzia Anizkoitzen Analisian lortutako inertzi tasen berdintasuna eta proposatu zuen $\frac{1}{\mathrm{Q}}$ baino handiagoak diren balio propioak soilik aztertzea eta balio bakoitzari ondoko inertzia egokitzea:

$$
\rho(\lambda)=\left(\frac{\mathrm{Q}}{\mathrm{Q}-1}\right)^{2}\left(\lambda-\frac{1}{\mathrm{Q}}\right)^{2},
$$

non Q aldagai aktiboen kopurua den.

Ardatz faktorialak interpretatzeko aldagaien ekarpen absolutuak erabili behar dira, aldagai bakoitzak azaltzen duen ardatz faktorialaren inertzi portzentajea adierazten baitute.

Korrespondentzia Analisian askotan agertzen den fenomenoa «Guttmanen efektua» da. Efektu hau sortzen da zutabe zein lerroetan ordenako egiturak egonik biak elkarturik daudenean. Egitura horren ondorioz, lerroak eta zutabeak lehenengo ardatzaren ordenaren arabera berrantolatzen baditugu, taula berriaren diagonaletik hurbil dauden elementuen balioak han- 
diak dira eta urrun daudenak, aldiz, nuluak edo ia nuluak. Horrelako egiturak adierazten du bigarren ardatza lehenengo ardatzaren bigarren mailako funtzio polinomikoa dela eta horregatik, modalitateek parabola bat deskribatzen dute lehenengo plano faktorialean.

\section{Balorazio-adierazle orokorraren eraikuntza}

Korrespondentzia Anizkoitzen Analisiaren bidez lortutako emaitzetan oinarrituta, balorazio-adierazle orokorra sortu dugu. Hori egiteko, lehendabizi, aldagai aktiboetako modalitate bakoitzari bere lehenengo koordenatu faktoriala esleitu diogu eta banakoaren puntuazio globala, galdera aktibo ezberdinetan aukeratutako modalitateen lehenengo koordenatu faktorialen batez besteko aritmetiko bezala definitu da, ardatz honek azaltzen duen desbiderapen estandarraren alderantzizkoaz biderkatuz.

Banako bakoitzaren puntuazio globala kalkulatu eta gero, Korrespondentzia Anizkoitzen Analisian lortutako koordenatuen balio maximo eta minimoak kontuan izanda, transformazio lineal bat egin dugu, balorazioadierazle orokorra 0tik 100era doan adierazlea bilakatuz.

Ondoren, eraikitako balorazio-adierazle orokorraren deskribapena egin dugu eta era berean, baita, sortutako adierazlea, inkestan zegoen prestakuntzaren balorazio orokorrari buruzko 10. galderan jasotako emaitzekin konparatu ere.

\section{Adierazle klasikoarekiko konparaketa}

Balorazio-adierazle klasikoa, aldagai aktiboetako modalitate bakoitzari 0-1-2-3 balioak esleituz lortzen da, kasu honetan ebaluazio-galderetarako erantzun aukerak 4 direla kontuan hartuta. Ondoren, banakoaren puntuazio globala, ebaluazio-galdera ezberdinetan aukeratutako modalitateen balioen batezbesteko aritmetikoaren bidez lortzen da.

Behin hori kalkulatuta, transformazio lineal bat egin dugu balorazioadierazle klasikoa ulergarriagoa den [0-100] bitarteko adierazle bihurtuz; guk eraikitako balorazio-adierazle orokorrarekin alderatu dugu.

\section{Eraikitako balorazio-adierazle orokorrean eragina duten faktoreak}

BAMEen ezaugarrien arabera banatutako balorazio-adierazle orokorrak, BAMEek ahalbidetzen du beraien egoeraren arabera programari eman dioten balorazio ezberdinak nabarmentzea. Horregatik, ezaugarri desberdinak dituzten BAMEek programa modu berdintsu batean baloratzen duten ala ez aztertzeko, kutxa diagramak eta Kruskal-Wallis eta Wilcoxon-en test ezparametrikoak erabili ditugu, erabilienak diren ohiko estatistiko deskribatzaileez gain.

Azterketa estatistikoak R 2.14.0 pakete estatistikoaren bidez egin ditugu. 


\section{EMAITZAK}

\section{Aldagai anitzeko azterketa deskribatzailea}

Korrespondentzia Anizkoitzen Analisia egitean, iritzi-aldagaiak (1, 6, 7, $8,9,10,12,13,14,15,17$. galderak, 1. Eranskinean laburturik daudenak) aktibotzat hartu ditugu, eta BAMEek inkesta bete zuten urtea, zerbitzuak antolaturiko saio klinikoen maiztasuna eta bestelako aldagai objektiboak, aldiz, argigarritzat hartu ditugu. Denetara, aldagai aktiboak eta argitzaileak, 11 eta 13 izan dira, hurrenez hurren.

Analisi honetan lortutako lehenengo balio propioak eta Bénzecrik proposaturiko inertzi tasak 1. taulan ageri dira. Ikus daitekeenez, lehenengo bi ardatzek sortutako planoaren bidez, inertziaren \% 78.5a azaltzen da.

1. taula. $\lambda>(1 / 11)$ diren lehenengo bi balio propioek azaldutako inertzia tasak.

\begin{tabular}{ccc}
\hline Balio propioa & Inertzia tasa & Inertzia tasa metatua \\
\hline 0.266025 & 56.4 & 56.4 \\
0.104043 & 22.06 & 78.5 \\
$\ldots$ & $\ldots$ & $\ldots$ \\
& & 100 \\
\hline
\end{tabular}

Bigarren taulan, lehenengo bi ardatzetako ekarpen absolutuak agertzen dira.

2. taula. Lehenengo bi ardatz faktorialei dagozkien ekarpen absolutu nagusiak.

\begin{tabular}{lcc}
\hline & \multicolumn{2}{c}{ Ekarpen absolutuak } \\
\cline { 2 - 3 } & 1 & 2 \\
\hline 1. Zerbitzuak zure prestakuntzaz duen ardura. & 57 & 36 \\
6. Asistentziazko jarduera gainbegiratzea. & 54 & 37 \\
7. Asistentziazko prestakuntzaren balorazioa. & 58 & 47 \\
8. Irakaskuntza prestakuntzaren balorazioa. & 59 & 37 \\
9. Etika prestakuntzaren balorazioa. & 47 & 28 \\
10. Oro har, zerbitzuan jasotako prestakuntzaren balorazioa. & 59 & 43 \\
12. Tutoreak irakaskuntzaren gainean duen ardura. & 33 & 14 \\
13. Tutorearekin daukazun asetasun maila. & 29 & 12 \\
14. Medikuek daukaten asistentziazko gainbegiratzearen balorazioa. & 48 & 28 \\
15. Pertsonal medikoarekin daukazun asetasun maila. & 43 & 29 \\
17. Ikerketa prestakuntzaren balorazioa. & 29 & 11 \\
\hline
\end{tabular}


Lehenengo plano faktorialeko adierazpide grafikoa aztertzen badugu (1. irudia), berehala konturatuko gara Guttmanen efektua nabaria dela. Lehenengo bi ardatzen eraginez, lehenengo planoan modalitateek parabola antzeko bat irudikatzen dute, baina lehenengo ardatzean proiektatzen baditugu, oso garbi agertzen da ebaluazio eskala, negatiboenetik positiboenera.

Galdera guztien modalitateek deskribatzen dituzten parabolak oso antzekoak dira. Horrek, adierazten du batera doazela arlo ezberdinetako iritziak.

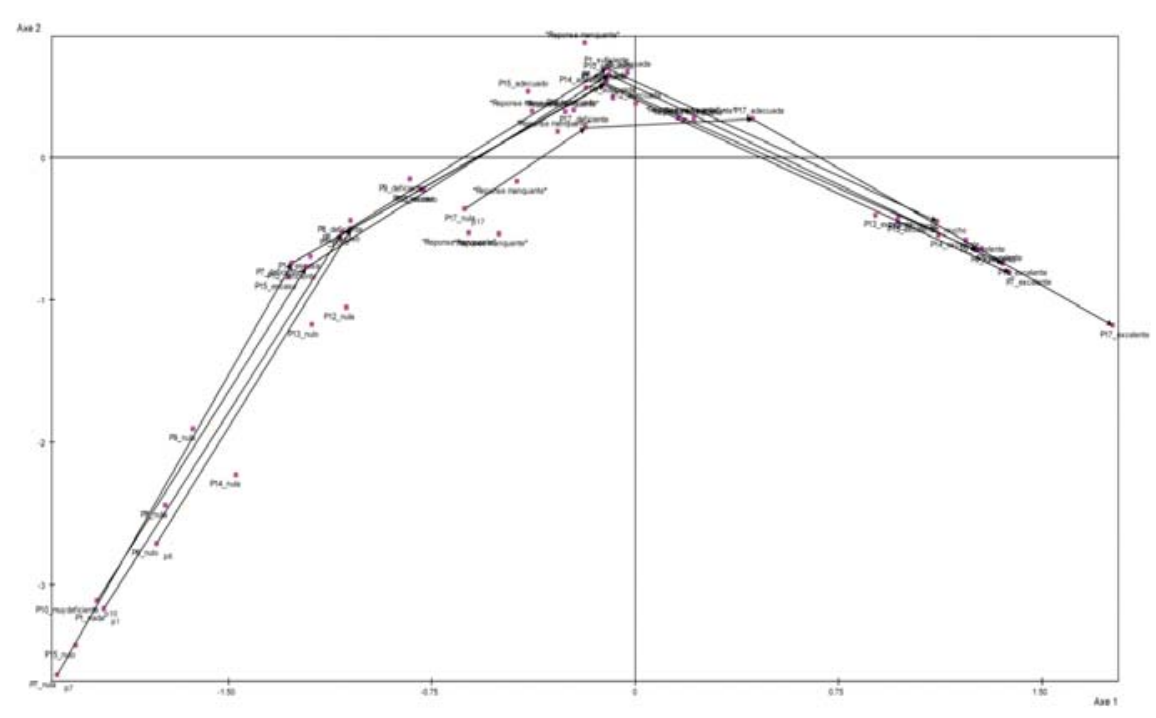

1. irudia. Aldagai aktiboen adierazpen grafikoa, lehenengo plano faktorialean.

\section{Balorazio-adierazle orokorraren eraikuntza}

Korrespondentzia Anizkoitzen Analisia egin ondoren, balorazio-adierazle orokorra eraiki dugu. Hau da,

$$
\text { Puntuazio globala }=\frac{t_{1}+t_{6}+t_{7}+t_{8}+t_{9}+t_{10}+t_{12}+t_{13}+t_{14}+t_{15}+t_{17}}{k \cdot \sqrt{\lambda_{1}}} .
$$

$t_{i}=i$. galderan aukeraturiko modalitatearen koordenatua.

$k=$ aldagai aktiboak $=11$.

$\lambda_{1}=$ lehen balio propioa.

$\sqrt{\lambda_{1}}=0.5598$.

Behin banako bakoitzaren puntuazio globala kalkulatuta, kontuan hartuko dugu puntuazio maximoa 2.88 eta minimoa -3.90 direla, eta 
balorazio-adierazle orokorra 0tik 100era doan adierazle bihurtuta, KAadierazlea deituko diogu.

KA-adierazleak ez dio banaketa normalari jarraitzen (KolmogorovSmirnoven testa, $p=0.0003$ ), eta horrela izanik test ezparametrikoak erabiliko dira. Batez bestekoa 57.549 puntukoa da, alegia, nahiko altua, eta mediana eta lehenengo koartila 55.903 eta 45.665 puntuetan kokatzen dira, hurrenez hurren. Beraz, adierazlea ez dago oso sakabanatuta, eta nahiko simetrikoa da. 3. taulan ageri da eraikitako balorazio-adierazle orokorraren deskribapen estatistikoa.

3. taula. Eraikitako balorazio-adierazle orokorraren deskribapen estatistikoa.

\begin{tabular}{ccccccccc}
\hline & $\mathrm{N}$ & Minimoa & Maximoa & $\begin{array}{c}\text { Batez- } \\
\text { bestekoa }\end{array}$ & $\begin{array}{c}\text { Desb. } \\
\text { est. }\end{array}$ & $\mathrm{Q}_{1}$ & Mediana & $\mathrm{Q}_{3}$ \\
\hline KA-adierazlea & 849 & 2.565 & 100 & 57.549 & 19.726 & 45.665 & 55.903 & 69.236 \\
\hline
\end{tabular}

KA-adierazlearen eraginkortasuna eta fidagarritasuna, inkestan zegoen prestakuntzaren balorazio orokorrari buruzko 10. galderan jasotako emaitzekin konparatuz agerian jarri dugu.

4. taulan aurkezten da KA-adierazlearen deskribapen estatistikoa, 10. galderaren modalitateen arabera.

4. taula. Balorazio-adierazle orokorraren, eta inkestako prestakuntzaren balorazio orokorrari buruzko 10. galderaren arteko konparaketa.

\begin{tabular}{crrrrrrrr}
\hline 10. galdera & $\mathrm{N}$ & $\begin{array}{c}\text { Batez- } \\
\text { bestekoa }\end{array}$ & $\begin{array}{c}\text { Desb. } \\
\text { est. }\end{array}$ & Minimoa & Maximoa & $\mathrm{Q}_{1}$ & Mediana & $\mathrm{Q}_{3}$ \\
\hline Bikaina & 184 & 84.143 & 11.23 & 54.458 & 100 & 76.820 & 85.747 & 93.816 \\
Egokia & 493 & 55.762 & 9.915 & 27.528 & 87.032 & 49.646 & 54.880 & 61.418 \\
Eskasa & 139 & 33.468 & 11.358 & 2.565 & 78.399 & 25.436 & 32.491 & 39.939 \\
\hline Oso eskasa & 14 & 17.673 & 9.701 & 5.302 & 34.993 & 8.856 & 17.539 & 25.238 \\
Erantzunik ez & 19 & 51.944 & 15.499 & 27.917 & 87.131 & 43.51 & 47.435 & 60.587 \\
\hline
\end{tabular}

Ikusi dugu talde desberdinen artean badaudela estatistikoki adierazgarriak diren desberdintasunak (Kruskal-Wallisen testa, $p<0.001$ ). Hots, ospitalean prestakuntza bikain bat jaso dutela dioten BAMEei, beste taldee- 
tako medikuei baino KA-adierazle handiagoa dagokie eta prestakuntza oso eskasa jaso dutela diotenei, beste taldekoei baino KA-adierazle txikiagoa. Hau da, BAMEei dagokien KA-adierazlea behera egiten doa jaso duten prestakuntza eskasagoa dela dioten heinean (2. irudia). Era horretan, egiaztatzen da KA-adierazlea BAMEek ospitalean jasotako prestakuntza ebaluatzeko tresna egokia dela. Aldiz, galdera horri erantzun ez dioten BAMEen kasuan, 2. irudiaren azken kutxan ikusten da KA-adierazlea oso sakabanatuta agertzen dela. Hau da, balorazio orokorreko 10. galderari erantzun ez diotenen artean, KA-adierazlearen balioak era guztietakoak izan dira eta ezin dugu horien barnean inolako joerarik sumatu.

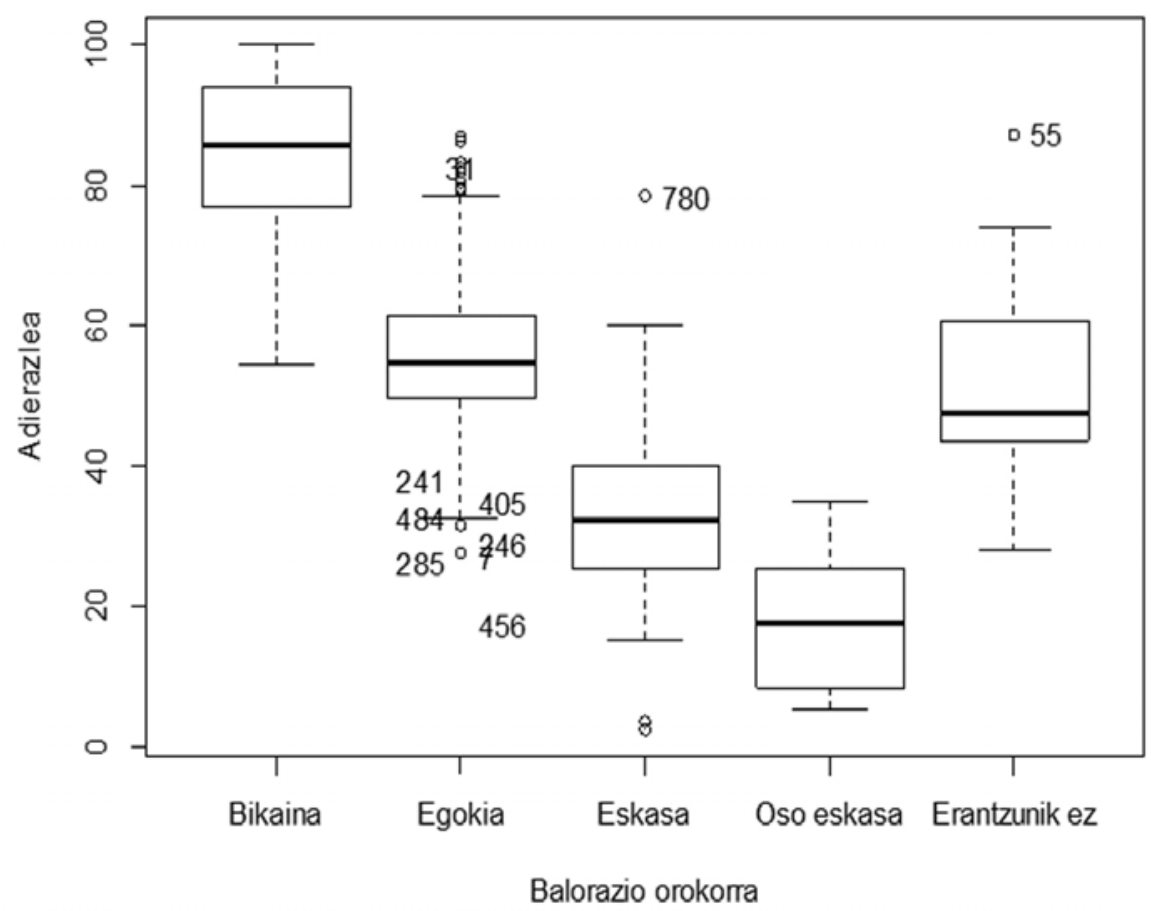

2. irudia. Balorazio-adierazle orokorraren, eta inkestako prestakuntzaren balorazio orokorrari buruzko galderaren arteko konparaketa.

\section{Adierazle klasikoarekin konparaketa}

Gure balorazio-adierazlearen eraginkortasuna egiaztatzen jarraitzeko, oso erabilia den beste adierazle batekin alderatu dugu, adierazle klasikoarekin, alegia. 
5. taulak aurkezten ditu bi adierazleen arteko konparaketaren emaitzak.

5. taula. Bi adierazleen arteko konparaketa.

\begin{tabular}{cccccccccc}
\hline & $\mathrm{N}$ & $\begin{array}{c}\text { Galdutako } \\
\text { balioak }\end{array}$ & $\begin{array}{c}\text { Batez- } \\
\text { bestekoa }\end{array}$ & $\begin{array}{c}\text { Desb. } \\
\text { est. }\end{array}$ & Min. & Max. & $\mathrm{Q}_{1}$ & Mediana & $\mathrm{Q}_{3}$ \\
\hline $\begin{array}{c}\text { KA- } \\
\text { adierazlea }\end{array}$ & 849 & 0 & 57.549 & 19.726 & 2.565 & 100 & 45.665 & 55.903 & 69.236 \\
$\begin{array}{c}\text { Adierazle } \\
\text { klasikoa }\end{array}$ & 544 & 305 & 63.391 & 19.541 & 3.030 & 100 & 51.515 & 63.636 & 75.758 \\
\hline
\end{tabular}

Adierazle klasikoaren kasuan, ikusten dugu balioen \%35.92ak galdutako balioak direla, 849 balioetatik 305 balio hain zuzen. Hau, inkesta bete duten 305 BAMEek iritzi-aldagairen bat erantzun gabe utzi dutelako gertatu da. Hori dela eta, ez da banako hauentzako puntuazio globalik lortzen.

Arazo hau konpontzeko eta banako guztiei dagokien balorazio-adierazlea egokitu ahal izateko, galdutako balioen inputazio teknikak erabili beharko genituzke, baina sarritan teknika hauek ez dira aplikatzen errazak.

Ordea, arazo hau ez da KA-adierazlearen kasuan gertatzen. Izan ere, Korrespondentzia Anizkoitzen Analisiak ahalbidetzen digu erantzunik eza galdera bakoitzaren beste modalitate bat balitz bezala tratatzea. Hau horrela izanda, erantzunik ezak dagokion koordenatu faktoriala esleituta dauka eta inkesta bete duten banako guztiek dagokien balorazio-adierazlea eskuratzen dute.

Aldi berean, 5. taulan agerian geratzen da adierazle klasikoaren kasuan estatistiko guztien balioak handiagoak direla. Hau gertatzen da adierazle hau eraikitzeko orduan galdera bakoitzeko modalitateen kopuruak ez direlako kontuan hartzen. Hau dela eta, adierazle klasikoa gurea baino baikorragoa dela esan genezake.

KA-adierazleak galdera bakoitzeko kontuan hartzen ditu modalitateen kopuruak eta horrela, balorazio oso ezkorrak isolatzeko eta era independentean aztertzeko aukera ematen digu.

\section{Eraikitako balorazio-adierazle orokorrean eragina duten faktoreak}

Ohiko estatistiko deskribatzaileak, kutxa diagramak eta Kruskal-Wallis eta Wilcoxonen test ezparametrikoak erabiliz, eraikitako balorazio-adierazle orokorrean faktoreek duten eragina aztertu dugu eta lortutako ondorioak 6. taulan biltzen dira. 
6. taula. Balorazio-adierazle orokorrean eragina duten eta ez duten faktoreak.

Balorazio-adierazle orokorrean eragina duten faktoreak:

- Ebaluazio-urtea eta egonaldi-urtea.

- Saio kliniko, espezifiko eta bibliografikoen antolaketa, eta zerbitzu arteko saioetan eta ikerketan duten parte hartzea.

- Jardueraren programarekiko egokitzapena.

- Tutorearen ezaguera eta berarekin duten asetasun maila.

Balorazio-adierazle orokorrean eraginik ez duten faktoreak:

- Prestakuntza-programaren ezaguera eta jasotzea.

- Zerbitzuan egondako hilabete kopurua.

Beraz, BAMEek daukaten egoeraren arabera, programari ematen dioten balorazioa desberdina da eta analisi honek, aukera ematen digu ebaluazio hobeak lortzeko hobetu beharreko arloak zeintzuk diren aurkitzeko.

\section{EZTABAIDA}

Balorazio-inkesta honetan gertatzen den moduan, aldagai kualitatiboak ditugunean, Korrespondentzia Anizkoitzen Analisia da dimentsioa murrizteko teknikarik egokiena. Teknika horren bidez lorturiko faktoreek, Guttmanen efektua dela kausa, BAME programaren ebaluazio eskala bat adierazten dute eta aukera ematen digu balorazio-adierazle orokor bat eraikitzeko, KA-adierazlea deitu duguna eraikitzeko hain zuzen.

Balorazio-adierazle hori programarekiko asetze maila neurtzeko tresna egokia dela egiaztatu dugu, inkestan zegoen prestakuntzaren balorazio orokorrari buruzko 10. galderan jasotako emaitzekin konparatuz.

KA-adierazlea ohikoa den beste adierazle batekin alderatu dugu. Inkesta bete duten pertsona guztietarako adierazlea lortzea da Korrespondentzia Anizkoitzen Analisitik abiatuz sortu dugun KA-adierazlearen abantaila nagusia. Izan ere, Korrespondentzia Anizkoitzen Analisiak, aldagai guztien modalitate modura aztertzen du erantzunik eza, eta hutsik utzitako galderek ez dute arazorik sortzen.

Gainera, KA-adierazleak, batik bat muturreko balio negatiboak bereizteko aukera ematen du, hauen analisia aparteko era batean egitea baimenduz. Horregatik, egiaztaturik geratu da balorazio-adierazle klasikoak baino abantaila handiagoak dituela eta inferentzia egiterako orduan fidagarriagoa dela.

Faktore desberdinek adierazlean duten eragina aztertu dugu, eta BAMEen asetze zein atsekabeen jatorria zein den nabarmendu ere. KA-adierazlea zerbi- 
tzu bakoitzerako kalkula daiteke eta ospitaleko irakaskuntza unitateari ahalbidetzen dio BAME programan beharrezkoak diren hobekuntzak proposatzea.

$\mathrm{R}$-project programak aukera eman digu diseinaturiko KA-adierazlea automatikoki kalkulatzeko.

Lorturiko KA-adierazlea erabil daiteke horrelako inkestak egiten diren beste EAEko ospitaletan. Gainera, posible da R-n egindako programa antzekoak diren beste inkesta batzuetara moldatzea, eta orokorrean, inkesta baten emaitzak jaso eta laburtzen dituzten adierazleen eraikuntzetara moldatzea ere.

\section{BIBLIOGRAFIA}

[1] AREDA (Asociación de Redes de Comisiones de Docencia y Asesoras). 2007. «La evaluación de la formción especializada como garantía de la calidad del sistema de salud». Educación Médica; 10 (1): 16-25.

[2] BENZÉCRI J.P. 1979. «Sur le Calcul des taux d'Inertie dans l'Analyse d'un Questionaire». Cahiers de l'Analyse des Données, IV (3), 55-71.

[3] BENZÉCRI JP. 1980. L'Analyse des Données tome 2: l'analyse des correspondances, Dunod, Paris:

[4] ESCOFIER B., PAGÉS J. 1992. Análisis factoriales simples y múltiples. Servicio Editorial UPV/EHU, Leioa.

[5] GRANDE I., ABASCAL E. 2005. Análisis de encuestas. ESIC, Madrid.

[6] GREENACRE M. 2002. «Correspondence analysis of the Spanish National Health Survey». Gaceta Sanitaria, 16 (2), 160-70.

[7] GREENACRE M., PARDO R. 2006. Subset Correspondence Analysis: Visualizing Relationships Among a Selected Set of Response Categories from a Questionnaire Survey. Sociological Methods and Research, 35, 193-218.

[8] GREENACRE M. 2008. La práctica del análisis de correspondencias. Fundación BBVA, Bilbao.

[9] MORÁN-BARRIOS J., RUIZ DE GAUNA-BAHILLO P. 2010. «iReinventar la formación de médicos especialistas? Principios y retos». Nefrologia; 30 (6), 604-12.

[10] NENADIC O., GREENACRE M. 2007. «Correspondence Analysis in R, with Two- and Three-dimensional Graphics: The ca Package». Journal of Statistical Software, 20 (3), 1-13.

[11] PIJOÁN J.I., URKAREGI A., MORÁN J.M. 2001. «Evaluación por los médicos internos residentes de la formación recibida en los servicios hospitalarios: una herramienta de monitorización». Gaceta Sanitaria; 15 (5), 432-440.

[12] QUINTANA J.M., GONZÁLEZ N., BILBAO, A., AIZPURU, F., ESCOBAR, A., ESTEBAN, C., SAN-SEBASTIÁN, J.A., DE-LA SIERRA, E., THOMPSON, A. 2006. «Predictors of patient satisfaction with hospital health care». BMC Health Services Research, 6:102.

[13] R-Project: http://www.r-project.org. Eguneratze-data: 2013-09-15. 


\section{ERANSKINA}

\section{Barruko mediku egoiliarrek zerbitzuan jasotako prestakuntzaren balorazioa. Gurutzetako Unibertsitate Ospitalea}

Identifikazio zenbakia:

Ebaluazio-urtea:

Egonaldi-urtea:

Zerbitzua:

Zerbitzuan egondako hilabete kopurua:

Espezialitatea:

1. Zerbitzua zure prestakuntzaz arduratzen al da?

2. Zerbitzuak saio klinikoak antolatzen al ditu?

3. Zerbitzuak saio espezifikoak antolatzen al ditu?

4. Zerbitzuak saio bibliografikoak antolatzen al ditu?

5. Nolakoa da zerbitzuak zerbitzu arteko saioetan daukan parte hartzea?

6. Zein da asistentziazko jardueraren gainbegiratzeari buruz duzun balorazioa?

7. Zein da asistentziazko prestakuntzari ematen diozun balorazioa?

8. Zein da irakaskuntza-prestakuntzari ematen diozun balorazioa?

9. Zein da etika-prestakuntzari ematen diozun balorazioa?

10. Oro har, zein da zerbitzuan jasotako prestakuntzari ematen diozun balorazioa?

11. Ba al dakizu zure tutorea nor den?

12. Zein da tutoreak irakaskuntzaren gainean duen ardura?

13. Zenbatekoa da tutorearekin daukazun asetasun maila?

14. Zein da medikuek daukaten asistentziazko gainbegiratzeari ematen diozun balorazioa?

15. Zenbatekoa da pertsonal medikoarekin daukazun asetasun maila?

16. Zenbatekoa da zerbitzuak ikerketan daukan parte hartzea?

17. Zein da ikerketa prestakuntzari ematen diozun balorazioa?

18. Prestakuntza-programa ezagutzen al duzu?

19. Prestakuntza-programa eman al dizute?

20. Zure jarduera-programara egokitzen al da?

* Galderak jatorrizko ordenan ageri dira, baina laburturik daude. Galdetegiaren bertsio laburtua. 